\title{
Estudo de aceitabilidade das intervenções psicológicas via telefone para sobreviventes de cancro dos Açores
}

\author{
Azorean cancer survivors' acceptability of psychological \\ telephone-based interventions
}

\section{Marina Sousa ${ }^{1}$ (1) \\ Helena Moreira ${ }^{2}$ (]) Maria Cristina Canavarro 3 (1) Célia Barreto Carvalho 4 (1)}

'Autora principal para correspondência. Departamento de Psicologia, Faculdade de Ciências Sociais e Humanas, Universidade dos Açores (Açores). Centro de Investigação em Neuropsicologia e Intervenção Cognitivo-Comportamental, Faculdade de Psicologia e de Ciências de Educação da Universidade de Coimbra (Coimbra). Portugal. marina.c.sousa@uac.pt ${ }^{2,3}$ Centro de Investigação em Neuropsicologia e Intervenção Cognitivo-Comportamental, Faculdade de Psicologia e de Ciências de Educação da Universidade de Coimbra (Coimbra). Portugal. hmoreira@fpce.uc.pt, mccanavarro@fpce.uc.pt

${ }^{4}$ Departamento de Psicologia, Faculdade de Ciências Sociais e Humanas, Universidade dos Açores (Açores). Centro de Investigação em Neuropsicologia e Intervenção Cognitivo-Comportamental, Faculdade de Psicologia e de Ciências de Educação da Universidade de Coimbra (Coimbra). Portugal. celia.mo.carvalho@uac.pt

RESUMO | INTRODUÇÃO: As intervenções com recurso à tecnologia têm mostrado ser promissoras para ultrapassar algumas barreiras de acesso aos cuidados dos sobreviventes de cancro de regiões mais isoladas. Os estudos de aceitabilidade e das preferências dos sobreviventes relativamente a estas intervenções são escassos em Portugal e inexistentes nos Açores. OBJETIVOS: Este estudo pretendeu avaliar: i) os comportamentos de procura de ajuda dos sobreviventes de cancro dos Açores e as barreiras à procura de ajuda; e ii) o grau de aceitabilidade e as preferências destes sobreviventes relativamente ao desenvolvimento, implementação e participação numa intervenção psicológica via telefone. MÉTODO: Este estudo envolveu 173 sobreviventes de cancro dos Açores, recrutados num hospital público regional, numa unidade de saúde regional e numa instituição sem fins lucrativos. Recorreu-se a um questionário construído para o efeito, sendo os dados tratados com estatística descritiva. RESULTADOS: O apoio psicológico mostrou-se um comportamento de ajuda aceitável para os sobreviventes, sendo as barreiras à procura de ajuda de índole estrutural/prática e de conhecimento as mais endossadas pelos participantes. A maioria da amostra considerou útil uma intervenção psicológica via telefone, reportando ser provável participar. As sessões com uma duração situada entre os 30 a 45 minutos e com uma periodicidade quinzenal foram os aspetos preferenciais dos participantes. DISCUSSÃO E CONCLUSÃO: Espera-se que os resultados deste estudo possam orientar o desenvolvimento de uma intervenção via telefone que responda flexivelmente às necessidades dos sobreviventes dos Açores e facilite o suporte a prestar-Ihes, integrando as suas preferências no desenho de uma intervenção desta natureza.

PALAVRAS-CHAVE: Sobreviventes. Cancro. Ilhas. Preferências. Comportamento. Intervenção psicológica.
ABSTRACT | INTRODUCTION: Technology-based interventions are promising for overcoming some barriers that cancer survivors from isolated regions face in accessing health-care. No studies are exploring the acceptability and preferences concerning these interventions in Portugal and even in the Azores. OBJECTIVES: This study aims to evaluate: i) Azorean cancer survivors' help-seeking behaviors and barriers for seeking help; and ii) survivors' acceptability and preferences concerning development, implementation, and participation in the psychological telephone-based intervention. METHOD: This study included a sample of 173 cancer survivors from the Azores archipelago (Portugal) recruited from a local oncological hospital and health unit. Data were collected through a questionnaire built for this purpose and analyzed with a descriptive statistic. RESULTS: Psychological support was an accepted help-seeking behavior and the structural/practical and knowledge barriers for seeking help were the more endorsed by participants. The majority of the sample considered a psychological telephone-based intervention useful; reporting being likely participating. The length of the sessions ranging from 30 to 45 minutes and fortnightly were the participants' preferences. DISCUSSION AND CONCLUSION: Results may guide the development of a psychological telephone-based intervention for cancer survivors from the Azores, which can respond flexibly to their needs and facilitating the support to provide them, including their preferences when designing an intervention of that nature.

KEYWORDS: Survivors. Cancer. Islands. Preferences. Behavior. Psychological intervention. 


\section{Introdução}

O avanço nos tratamentos oncológicos tem conduzido a um aumento do número de sobreviventes de cancro. Esta tendência tem-se verificado na Europa, nomeadamente em Portugal (Allemani et al., 2018), com taxas de sobrevivência situadas nos $60-69 \%$ para os cancros de colón e reto; nos $85 \%$ para a mama; nos cerca 90\% para a próstata (Concord-3; Allemani et al., 2018). No arquipélago dos Açores as taxas de sobrevida aos 5 anos também têm vindo a registar um aumento para as neoplasias mais incidentes na Região, como é o caso do cancro da próstata (93\%; Allemani et al., 2018).

O impacto físico (e.g., fadiga, dor, redução da mobilidade, problemas de fertilidade) e psicossocial (e.g., medo de recidivas, ansiedade, depressão, dificuldades profissionais e financeiras) sentido pelos sobreviventes de cancro (i.e., todos aqueles que já recuperaram de qualquer evidência de doença, que se encontram numa fase sem risco ou com risco mínimo de recorrência, e que apresentam restauro da sua saúde nas suas componentes física, desenvolvimental e psicossocial; OMS, 2008) encontra-se bem fundamentado na literatura (e.g., Frensham et al., 2018; Loughery \& Woodgate, 2015; Inhestern et al., 2017; Jean \& Syrjala, 2017; Oberoi et al., 2017; Ojewole et al., 2018; Price \& Brunet, 2019; Stanton et al., 2015; Yi \& Syrjala 2017).

A área geográfica onde o sobrevivente reside parece ter influência no impacto físico e psicossocial sentido e no ajustamento psicológico à sobrevivência (Burris \& Andrykowski, 2010; Youl et al., 2016). Os estudos têm vindo a apontar que os sobreviventes de meios rurais ou mais isolados, comparativamente aos de meios urbanos, experienciam, por um lado, mais necessidades ao nível da informação, da continuidade do suporte/cuidados e do acesso a equipas e a serviços de saúde especializados (suporte psicológico, social; Youl et al., 2016) e, por outro lado, um funcionamento mental mais pobre (e.g., mais sintomatologia ansiosa e depressiva; Lashbrook et al., 2018).

\section{Barreiras aos Comportamentos de Procura de Ajuda dos Sobreviventes Oncológicos}

No entanto, e mesmo experienciando problemas emocionais ou psicológicos, alguns sobreviventes optam por não procurar ajuda psicológica (Leppin et al., 2019; Matsui \& Taku, 2016). No caso dos sobreviventes de meios rurais ou mais isolados, algumas barreiras aos comportamentos de procura de ajuda (i.e., qualquer conduta ativa por parte do indivíduo de procurar ajuda perante uma situação física, psicológica ou emocionalmente desconfortável; Cornally \& McCarthy, 2011) têm sido identificadas: a) maiores limitações no acesso a suporte psicológico e/ou grupos de suporte, devido às longas distâncias até aos serviços de saúde, à indisponibilidade de transportes, e aos recursos financeiros limitados; b) número mais reduzido de profissionais especializados em saúde mental (psicólogos, psiquiatras); e c) estigma percecionado no acesso aos serviços de saúde mental e à partilha de problemas psicológicos ou emocionais com os profissionais de saúde (Youl et al., 2016).

\section{A Intervenção Psicológica para Sobreviventes de Cancro}

Em Portugal, os orçamentos governamentais disponíveis para a intervenção em saúde mental são reduzidos, o que pode ser um desafio na operacionalização de intervenções de suporte (Mendes-Santos et al., 2019). Para além disso, com o passar dos anos, muitos sobreviventes deixam de se deslocar a consultas de follow-up de forma tão periódica como acontecia na fase logo após o término dos tratamentos. Este aspeto pode, também, condicionar a definição de estratégias interventivas mais inovadoras capazes de chegar aos sobreviventes que necessitam de ajuda, reduzindo custos para os serviços de saúde, mas mantendo a qualidade do suporte a prestar (MendesSantos et al., 2019).

As próprias características geográficas da região onde o sobrevivente reside (e.g., ruralidade, isolamento, dispersão geográfica) podem também influenciar a concretização de intervenções psicológicas (Cavanagh et al., 2016; Coffey et al., 2016), onde as barreiras práticas à procura de ajuda se impõem. Nos Açores, o número reduzido de equipas especializadas em saúde mental e os constrangimentos impostos pela insularidade no acesso aos serviços de saúde (e.g., distâncias até aos hospitais centrais, carência de transportes, custos envolvidos na deslocação dentro e fora da Região), tornam mais desafiante o desenho e a implementação de intervenções psicológicas que permitam ultrapassar estes constrangimentos. 
A Utilização da Tecnologia na Intervenção Psicológica para Sobreviventes de Cancro

Como forma de responder a alguns dos aspetos acima referidos, os estudos de revisão mais recentes têm vindo a avaliar os efeitos da utilização da tecnologia (e.g., telemedicina, e-health, telefone, apps) na prestação de cuidados de suporte e de follow-up para sobreviventes de cancro (Crowder et al., 2019; Escriva et al., 2018; Forbes et al., 2019). Dadas as especificidades geográficas do arquipélago açoriano (e.g., dispersão geográfica) e, consequentemente, as barreiras geográficas, práticas/estruturais, que podem influenciar a procura de ajuda especializada, o recurso à tecnologia pode ser uma via promissora na prestação de apoio psicológico aos sobreviventes desta Região. No caso específico das intervenções psicológicas via telefone (e.g., Okuyama et al., 2015), os estudos sugerem tratar-se de uma forma conveniente e alternativa de ajudar os sobreviventes de cancro a lidar com as dificuldades psicossociais sentidas (e.g., ansiedade, depressão, distress, sentimentos de incerteza e medo da recorrência; Okuyama et al., 2015). Importa que, aquando do desenho de intervenções psicológicas desta natureza, a aceitabilidade (i.e., estado psicológico individual relacionado com a sua intenção e disposição de utilizar um determinado produto; Gattiker, 1984), e as preferências dos sobreviventes relativamente a este novo formato de intervenção não sejam descuradas (Escriva et al., 2018).

\section{O Presente Estudo}

A par deste quadro conceptual, os objetivos deste estudo são:

- Caracterizar as práticas atuais de utilização do telefone/telemóvel dos sobreviventes dos Açores;

- Caracterizar os comportamentos de procura de ajuda dos sobreviventes do arquipélago açoriano e as barreiras à intervenção presencial; e

- Explorar o grau de aceitabilidade e as preferências destes sobreviventes relativamente ao desenvolvimento, implementação e participação numa intervenção psicológica via telefone.
Método

\section{Participantes}

O presente estudo incluiu uma amostra de 173 sobreviventes de doença oncológica dos Açores-Portugal. Os critérios de inclusão na amostra foram os seguintes: a) ter idade igual ou superior a 18 anos; b) ser residente nos Açores; c) ser sobrevivente de doença oncológica (mesmo que mantenha terapêutica hormonal de manutenção); d) não apresentar sinais clínicos de doença oncológica, confirmados pelos devidos exames complementares de diagnóstico, encontrando-se apenas em seguimento; f) não possuir comprometimento cognitivo, físico e/ou psicológico; e g) saber ler e escrever português.

\section{Procedimentos}

A amostra do projeto foi recolhida entre março de 2017 e abril de 2019, no Serviço de Oncologia Médica do Hospital do Divino Espírito Santo de Ponta Delgada, EPE (SOM-HDES), no Núcleo Regional dos Açores da Liga Portuguesa Contra o Cancro (Delegações de São Miguel, Terceira e Faial) e na Unidade de Saúde da ilha das Flores. Para a prossecução do presente estudo foram obtidas todas as aprovações e cumpridos os procedimentos éticos previstos pelas Comissões de Ética das instituições envolvidas, pela Declaração de Helsínquia e pela Ordem dos Psicólogos Portugueses. Para aceder à amostra do estudo, os profissionais de saúde das instituições envolvidas (médicos oncologistas, enfermeiros e assistente social) efetuaram o primeiro contacto com todos os participantes, apresentando-Ihes o estudo e convidando-os a participar. Os participantes que manifestaram interesse em colaborar foram, posteriormente, contactados pela investigadora para ser agendado um encontro presencial para a recolha de dados em cada uma das instituições envolvidas ou no domicílio dos sobreviventes (apenas no caso de os participantes residirem na ilha de São Miguel). Foi formalizado o termo de consentimento informado com todos os participantes que aceitaram participar, sendo garantida a confidencialidade e o anonimato da informação recolhida. A recolha de dados foi concretizada através de um protocolo de avaliação, com um conjunto de instrumentos de autorrelato e do qual fazia parte os questionários para este estudo (cf. Instrumentos). 


\section{Instrumentos}

Questionário sobre informação sociodemográfica e clínica. Os dados sociodemográficos (e.g., idade, género, ilha de residência) e clínicos (e.g., diagnóstico, tratamentos recebidos) foram recolhidos e avaliados com recurso a um questionário de autorresposta desenvolvido pelas autoras do estudo.

Questionário para Estudo de Aceitabilidade Breve. Este questionário foi construído pelas investigadoras do presente estudo, com base no questionário desenvolvido para efeitos de avaliação dos padrões de utilização de recursos online e a aceitabilidade de ferramentas e-health por parte de mulheres em período perinatal (Fonseca et al., 2016). O instrumento era composto por questões de resposta fechada, para as quais o participante se devia posicionar em termos de concordância ou de aplicabilidade a si. As questões deste questionário encontravam-se organizados em quatro partes: a) Comportamentos de procura de ajuda; b) Padrões atuais de utilização de telefone ou telemóvel; c) Aceitabilidade do telefone ou telemóvel como meio para promover a adaptação psicológica dos sobreviventes de doença oncológica; e d) Construção de um programa de intervenção via telefone ou telemóvel para promover a adaptação psicológica dos sobreviventes de doença oncológica: preferências.

Na primeira parte do questionário encontrava-se um total de 20 itens relativos aos Comportamentos de procura de ajuda, para os quais o participante se tinha que posicionar em termos de aceitabilidade da procura de ajuda profissional para lidar com algum problema psicológico ou suprir alguma necessidade psicossocial decorrente da fase em que se encontra, no sentido de melhor a ela se adaptar. Os primeiros 2 itens avaliavam a posição do participante em termos da sua aceitabilidade (Totalmente aceitável a Nada aceitável) da toma de medicação (1 item) (e.g., ansiolíticos, antidepressivos) e do acompanhamento psicológico (1 item) para fazer face a algum problema psicológico ou necessidade. Os restantes 18 itens diziam respeito a barreiras/obstáculos que podem influir na procura e no acesso a ajuda profissional nos Açores ou nas diferentes ilhas do arquipélago e para os quais o participante se tinha que posicionar em termos da aplicabilidade de cada item para si (Não se aplica nada a mim a Aplica-se muito a mim). Estas barreiras poderiam ser atitudinais ("Ter receio do que os meus familiares e/ou amigos podem pensar por eu frequentar consultas de psicologia e/ou psiquiatria"), de conhecimento ("Não saber se os meus problemas/necessidades/dificuldades são suficientemente graves para pedir ajuda") e práticas/estruturais, ("Os serviços de psicologia e/ou psiquiatria ficarem muito distantes da minha zona de residência"; "Não ter serviços de transportes disponíveis para ir e voltar das consultas de psicologia e/ou psiquiatria"; "Mesmo colocando a possibilidade de ser acompanhado por um psicólogo e/ou psiquiatra noutra ilha, as deslocações serem muito caras e eu não as poder pagar").

Posteriormente, o questionário apresentava uma segunda parte relativa aos Padrões atuais de utilização de telefone ou telemóvel. Esta parte do questionário era composta por 6 itens, um para avaliar cada um dos seguintes aspetos: o padrão de utilização do telefone ou telemóvel e em que contextos (e.g., Não; Sim, só em casa; Sim, só no trabalho; Sim, em casa e no trabalho); a finalidade no uso do telefone ou telemóvel (e.g., Só para fins pessoais; Só para fins de trabalho; Para assuntos profissionais e pessoais); a facilidade na leitura e escrita de mensagens (e.g., Não; Sim, mas só consigo ler mensagens no telefone ou no telemóvel; Sim, leio e escrevo mensagens no meu telefone ou telemóvel); a cobertura de rede no local onde reside (e.g., Não; Sim, só em casa; Sim, só no trabalho; Sim, em casa e no trabalho); a frequência de utilização (e.g., Todos os dias; Menos de uma vez por ano); e competência percecionada na utilização do telefone ou telemóvel (Extremamente competente a Nada competente). Para cada item, o participante escolhia a opção de resposta que melhor se aplicava a si. 
A terceira parte deste questionário dizia respeito à Aceitabilidade do telefone ou telemóvel como meio para promover a adaptação psicológica dos sobreviventes de doença oncológica, com um total de 12 itens. Na primeira parte, eram apresentados 9 itens relativos às intervenções via telefone. Para cada um, o participante era convidado a expressar o seu grau de aceitabilidade relativamente ao mesmo (Discorda Fortemente a Concorda Fortemente) caso tivesse um problema psicológico (e.g., ansiedade, depressão), alguma necessidade psicossocial ou dificuldades em adaptar-se psicologicamente à sobrevivência (e.g., Eu recorreria a programas de intervenção via telefone ou telemóvel para me ajudar a lidar com os meus problemas psicológicos/necessidades psicossociais/ dificuldades de adaptação psicológica; Os programas de intervenção por telefone ou telemóvel seriam eficazes para resolver/aliviar os meus problemas psicológicos/necessidades psicossociais/dificuldades de adaptação psicológica; Eu recomendaria os programas de intervenção via telefone ou telemóvel a um amigo ou a outros sobreviventes com problemas psicológicos/necessidades psicossociais/dificuldades de adaptação psicológica; Se eu quisesse, eu seria capaz de participar em programas de intervenção via telefone ou telemóvel). Nos três itens seguintes o participante tinha que transmitir a sua perceção relativamente à eficácia deste género de intervenções (Nada eficaz a Muito eficaz), à sua utilidade (Nada útil a Muito útil) e à probabilidade em participar numa intervenção deste género (Nada provável participar a Muito provável participar).

A quarta e última parte do questionário era referente à Construção de um programa de intervenção via telefone ou telemóvel para promover a adaptação psicológica dos sobreviventes de doença oncológica. Esta última parte era constituída por 6 itens, um para avaliar cada um dos seguintes aspetos: informação que seria importante receber sobre o programa (e.g., Informação sobre quem construiu o programa; Instruções de funcionamento); utilidade de ser explicada a organização e o funcionamento do programa
(Não ou Sim); duração de cada sessão (e.g., Menos de 30 minutos; Entre 60 a 90 minutos); periodicidade de cada sessão (e.g., Semanal; Mensal); ser possuidor de e-mail pessoal (e.g., Não; Sim e consulto com frequência); e utilidade de receção de mensagens para relembrar as sessões (e.g., Não ou Sim) . Para cada item o participante era convidado a escolher a opção de resposta que fosse da sua preferência.

\section{Análises Estatísticas}

Todas as análises estatísticas foram conduzidas no software Statistical Package for the Social Sciences (SPSS, V.24, SPSS, Inc, Chicago, IL). As características sociodemográficas e clínicas da amostra em estudo foram obtidas através de análise descritiva. Esta análise foi igualmente levada a cabo para a caracterização dos padrões atuais de utilização do telemóvel, o endosso nas barreiras ao acesso a ajuda profissional especializada e os níveis de aceitabilidade. Recorreuse ao teste do Qui-Quadrado para comparar os grupos etários (19-50 anos, 51-65 anos, e > 65 anos), a escolaridade (ensino básico, ensino secundário e ensino superior), a ilha de residência (Grupo Oriental ilha de São Miguel; Grupo Central - ilhas Terceira e do Faial; e Grupo Ocidental - ilha das Flores), e o tempo de sobrevivência (menos de 5 anos e 5 anos ou mais) nas diferentes variáveis estudadas.

\section{Resultados}

\section{Caracterização da amostra}

Os participantes tinham idades compreendidas entre os 19 e os 86 anos $(M=55.65 ; S D=13.66)$, sendo a maioria do sexo feminino $(n=132,76.3 \%)$, residente na ilha de São Miguel $(n=93,53.8 \%)$, casada ou em união de facto $(n=104,60.1 \%)$, com o Ensino Básico $(n=114,65.9 \%)$ e a exercer trabalho remunerado $(n$ $=69,39.9 \%)$. As características sociodemográficas da amostra encontram-se na Tabela 1. 
Tabela 1. Características Sociodemográficas da Amostra

\begin{tabular}{|c|c|}
\hline & $\begin{array}{c}\text { Amostra Total } \\
(N=173)\end{array}$ \\
\hline Idade (anos) $M(S D)$; range & $\begin{array}{c}55.65(13.63) \\
19-86\end{array}$ \\
\hline \multicolumn{2}{|l|}{ Idade $n(\%)$} \\
\hline $19-50$ & $58(33.5)$ \\
\hline $51-65$ & $75(43.4)$ \\
\hline$>65$ & $40(23.1)$ \\
\hline \multicolumn{2}{|l|}{ Género $n(\%)$} \\
\hline Masculino & $41(23.7)$ \\
\hline Feminino & $132(76.3)$ \\
\hline \multicolumn{2}{|l|}{ Ilha de Residência (Grupo) $n$ (\%) } \\
\hline Grupo Oriental (São Miguel) & $93(53.8)$ \\
\hline Grupo Central (Terceira e Faial) & $57(32.9)$ \\
\hline Grupo Ocidental (Flores) & $23(13.3)$ \\
\hline \multicolumn{2}{|l|}{ Estado Civil $n(\%)$} \\
\hline Solteiro & $25(14.5)$ \\
\hline Casado / União de Facto & $104(60.1)$ \\
\hline Divorciado & $18(10.4)$ \\
\hline Viúvo & $26(15)$ \\
\hline \multicolumn{2}{|l|}{ Escolaridade $n(\%)$} \\
\hline Ensino Básico & $114(65.9)$ \\
\hline Ensino Secundário & $34(19.7)$ \\
\hline Ensino Superior & $25(14.5)$ \\
\hline \multicolumn{2}{|l|}{ Situação Profissional $n(\%)$} \\
\hline Empregado & $69(39.9)$ \\
\hline Reformado & $48(27.7)$ \\
\hline Reformado por invalidez & $30(17.3)$ \\
\hline Desempregado & $14(8.1)$ \\
\hline Outro & $12(7)$ \\
\hline \multicolumn{2}{|l|}{ Rendimento $n(\%)$} \\
\hline Menos de 500 euros & $29(16.8)$ \\
\hline Entre 500 e 1000 euros & $52(30.1)$ \\
\hline Entre 1001 e 2000 euros & $65(37.6)$ \\
\hline Entre 2001 e 3500 euros & $23(13.3)$ \\
\hline Mais de 3500 euros & $4(2.3)$ \\
\hline
\end{tabular}

Em termos de características clínicas, a maioria dos participantes é sobrevivente de cancro da mama $(n=85$, 49.1\%) e apresenta um tempo de sobrevida inferior a 5 anos $(n=83,48 \%)$. Na fase ativa da doença, a maioria da amostra realizou cirurgia $(n=103,59.5 \%)$ e tratamento adjuvante de quimioterapia e radioterapia $(n=68,39.3 \%)$. As características clínicas da amostra podem ser vistas na Tabela 2. 


\begin{tabular}{|c|c|}
\hline & $\begin{array}{l}\text { Amostra Total } \\
\qquad(N=173)\end{array}$ \\
\hline & $n(\%)$ \\
\hline \multicolumn{2}{|l|}{ Diagnóstico/Tipo de Cancro } \\
\hline Mama & $85(49.1)$ \\
\hline Hematológicos ${ }^{1}$ & $20(11.6)$ \\
\hline Digestivos $^{2}$ & $23(13.3)$ \\
\hline Reprodutores $^{3}$ & $16(9.2)$ \\
\hline Respiratórios ${ }^{4}$ & $15(8.7)$ \\
\hline Endócrinos 5 & $4(2.3)$ \\
\hline Outros $^{6}$ & $10(5.8)$ \\
\hline \multicolumn{2}{|l|}{ Sobrevivência (anos) } \\
\hline$<5$ anos & $83(48.0)$ \\
\hline$>5$ anos & $67(38.7)$ \\
\hline Desconhece & $23(13.3)$ \\
\hline \multicolumn{2}{|l|}{ Cirurgia } \\
\hline Sim & $103(59.5)$ \\
\hline Não & $70(40.5)$ \\
\hline \multicolumn{2}{|l|}{ Tratamentos Adjuvantes } \\
\hline Apenas Quimioterapia (QT) & $61(35.3)$ \\
\hline Apenas Radioterapia (RT) & $17(9.8)$ \\
\hline QT e RT & $68(39.3)$ \\
\hline QT e Transplante & $5(2.9)$ \\
\hline Nenhum & $22(12.7)$ \\
\hline
\end{tabular}

${ }^{1}$ Hematológicos: Linfoma Não Hodgkin, Linfoma Hodgkin, Leucemia

${ }^{2}$ Digestivos: estômago, intestino, pâncreas, vesícula, esófago, reto

${ }^{3}$ Reprodutores: ovários, útero, testículos próstata, pénis

${ }^{4}$ Respiratórios: nasofaringe, orofaringe, laringe, pulmão, cavidade oral

${ }^{5}$ Endócrinos: adenocarcinoma submandibular, glândulas adrenais, tiróide

${ }^{6}$ Outros: bexiga, cérebro, melanoma, osteossarcoma, desconhecido 


\section{Caracterização dos Padrões Atuais de Utilização de Telefone ou Telemóvel}

Verificou-se que $79.8 \%$ da amostra $(n=138)$ utiliza o telefone ou telemóvel em casa e no trabalho, sendo que $97.7 \%(n=169)$ utiliza para fins pessoais e profissionais, com uma frequência de utilização diária $(89 \%, n=154)$. A maioria da amostra $(64.7 \%, n=112)$ tem facilidade em ler e escrever mensagens no telefone ou telemóvel e possui cobertura de rede no local onde reside $(81.2 \%, n=142) .89 \%$ dos participantes $(n=154)$ considerou ser moderadamente a extremamente competente na utilização do telefone ou telemóvel (39.9\% moderadamente competente; $35.3 \%$ muito competente; $16.2 \%$ extremamente competente).

Quando se consideram as variáveis sociodemográficas, uma maior proporção de sobreviventes com idades compreendidas entre os 19 aos 50 anos $(X 2(4)=$ 14.76; $p=0.00$ ) usa o telefone em casa e no trabalho. De igual modo, foram também os sujeitos do grupo etário dos 19 aos 50 anos $(X 2(6)=53.62 ; p=0.00)$, a residir no Grupo Central $(X 2(6)=16.35 ; p=0.01)$, com o Ensino Secundário e Superior $(X 2(6)=29.26$; $\mathrm{p}=0.00$ ) que reportaram maior facilidade na leitura e escrita de mensagens no telefone ou telemóvel. Quanto à competência na utilização do telefone ou telemóvel, uma maior proporção de participantes do Grupo Central $(X 2(6)=22.25 ; p=0.00)$, com idades compreendidas entre os 19 e os 50 anos $(X 2(6)=$ 59.48; $p=0.00$ ) e com Ensino Secundário e Superior $(X 2(6)=12.45 ; p=0.05)$ reportou ser muito competentes nesta utilização. Relativamente às variáveis clínicas, houve uma diferença estatisticamente significativa na frequência de utilização do telefone, com uma maior proporção de participantes com uma sobrevida inferior a 5 anos a reportar utilizar todos os dias o telefone ou telefone ou telemóvel, comparativamente ao grupo de participantes com sobrevivência superior a 5 anos (X2 (2) $=12.20 ; p=0.00)$.

\section{Comportamentos de Procura de Ajuda e Barreiras à Procura de Ajuda}

Em termos gerais, a maioria dos participantes considerou o acompanhamento psicológico como uma forma aceitável para lidar com algum problema psicológico, para suprir alguma necessidade psicológica e/ou social decorrente da fase da sobrevivência, e para melhor se adaptar psicologicamente a esta fase (13.9\% moderadamente aceitável; $45.7 \%$ bastante aceitável; 38.7\% totalmente aceitável). Esta tendência foi, igualmente, verificada no que concerne à toma de medicação (27.7\% moderadamente aceitável; 38.2\% bastante aceitável; $23.1 \%$ totalmente aceitável).

Como se pode observar na Tabela 3, uma maior proporção de sujeitos a residir na ilha de São Miguel (Grupo Oriental) reportou considerar totalmente e bastante aceitável o recurso à medicação $(X 2(8)=$ 27.48; $p=0.02$ ) para fazer face a dificuldades psicológicas e/ou sociais que possam surgir na sobrevivência, sendo que uma maior percentagem de participantes dos Grupos Central e Oriental considerou o acompanhamento psicológico totalmente e bastante aceitável $(X 2(8)=18.22 ; p=0.02$ ). Não se observaram diferenças estatisticamente significativas nos comportamentos de procura de ajuda quando se consideraram os anos de sobrevivência. 
Tabela 3. Comportamentos de Procura de ajuda e diferenças relativamente à idade, à ilha de residência e à escolaridade

\begin{tabular}{|c|c|c|c|c|c|c|c|c|c|c|c|c|c|c|c|}
\hline & $\begin{array}{c}19-50 \\
(n=58)\end{array}$ & $\begin{array}{c}51-65 \\
(n=75)\end{array}$ & $\begin{array}{c}>65 \\
(n=40)\end{array}$ & $x^{2}$ & $p$ & $\begin{array}{c}\text { Grupo } \\
\text { Oriental } \\
(n=93)\end{array}$ & $\begin{array}{l}\text { Grupo } \\
\text { Central } \\
(n=33) \\
\end{array}$ & $\begin{array}{c}\text { Grupo } \\
\text { Ocidental } \\
(n=23)\end{array}$ & $x^{2}$ & $p$ & $\begin{array}{c}\text { Ensino } \\
\text { Básico } \\
(n=114)\end{array}$ & $\begin{array}{c}\text { Ensino } \\
\text { Secundário } \\
(\boldsymbol{n}=34)\end{array}$ & $\begin{array}{c}\text { Ensino } \\
\text { Superior } \\
(n=25)\end{array}$ & $x^{2}$ & $p$ \\
\hline & $n(\%)$ & $n(\%)$ & $n(\%)$ & & & $n(\%)$ & $n(\%)$ & $n(\%)$ & & & $n(\%)$ & $n(\%)$ & $n(\%)$ & & \\
\hline \multicolumn{16}{|l|}{$\begin{array}{l}\text { Toma de } \\
\text { Medicação }\end{array}$} \\
\hline $\begin{array}{l}\text { Totalmente } \\
\text { Aceitável }\end{array}$ & $18(31)$ & $17(22.7)$ & $5(12.5)$ & & & $16(17.2)$ & $22(38.6)$ & $2(8.7)$ & & & $28(24.6)$ & $8(23.5)$ & $4(16)$ & & \\
\hline Bastante Aceitável & $18(31)$ & $28(37.3)$ & $20(50)$ & \multirow[t]{4}{*}{13.80} & \multirow[t]{4}{*}{0.09} & $44(47.3)$ & $11(19.3)$ & $11(47.8)$ & 27.48 & 0.00 & $46(40.4)$ & $14(41.2)$ & $6(24)$ & \multirow[t]{4}{*}{14.23} & \multirow[t]{4}{*}{0.08} \\
\hline $\begin{array}{l}\text { Moderadamente } \\
\text { Aceitável }\end{array}$ & $11(19)$ & $24(32)$ & $13(32.5)$ & & & $23(24.7)$ & $15(26.3)$ & $10(43.5)$ & & & $30(26.3)$ & $6(17.6)$ & $12(48)$ & & \\
\hline Pouco Aceitável & $8(13.8)$ & $4(5.3)$ & $1(2.5)$ & & & $5(5.4)$ & $8(14)$ & $0(0)$ & & & $9(7.9)$ & $3(8.8)$ & $1(4)$ & & \\
\hline Nada Aceitável & $3(5.2)$ & $2(2.7)$ & $1(2.5)$ & & & $5(5.4)$ & $1(1.8)$ & $0(0)$ & & & $1(0.9)$ & $3(8.8)$ & $2(8)$ & & \\
\hline \multicolumn{16}{|l|}{ Apoio Psicológico } \\
\hline $\begin{array}{l}\text { Totalmente } \\
\text { aceitável }\end{array}$ & $28(48.3)$ & $28(37.3)$ & $11(27.5)$ & \multirow{5}{*}{12.18} & \multirow{5}{*}{0.14} & $31(33.3)$ & $33(57.9)$ & $3(13)$ & & & $40(35.1)$ & $16(47.1)$ & $11(44)$ & \multirow{5}{*}{8.97} & \multirow{5}{*}{0.32} \\
\hline Bastante Aceitável & $22(37.9)$ & $36(48)$ & $21(52.5)$ & & & $46(49.5)$ & $18(31.6)$ & $15(65.2)$ & & & $54(47.4)$ & $13(38.2)$ & $12(48)$ & & \\
\hline $\begin{array}{l}\text { Moderadamente } \\
\text { Aceitável }\end{array}$ & $5(8.6)$ & $11(14.7)$ & $8(20)$ & & & $14(15.1)$ & $5(8.8)$ & $5(21.7)$ & 18.22 & 0.02 & $10(16.7)$ & $3(8.8)$ & $2(8)$ & & \\
\hline Pouco Aceitável & $2(3.4)$ & $0(0)$ & $0(0)$ & & & $1(1.1)$ & $1(1.8)$ & $0(0)$ & & & $1(0.9)$ & $1(2.9)$ & $0(0)$ & & \\
\hline Nada aceitável & $1(1.7)$ & $O(0)$ & $0(0)$ & & & $1(1.1)$ & $0(0)$ & $0(0)$ & & & $0(0)$ & $1(2.9)$ & $0(0)$ & & \\
\hline
\end{tabular}


Tal como apresentado na Tabela 4, das 18 razões que podem dificultar a procura e o acesso a ajuda profissional nas diferentes ilhas do arquipélago, o maior endosso verificou-se ao nível das barreiras práticas/estruturais (30\% assinalou o item "Mesmo tendo a possibilidade de ter consultas gratuitas no Hospital ou nos Centros de Saúde, não ter acesso a estas consultas de forma rápida"; $28.3 \%$ assinalou o item "Mesmo colocando a possibilidade de ser acompanhado por um psicólogo e/ou psiquiatra noutra ilha, as deslocações serem muito caras e eu não as poder pagar"). As barreiras de conhecimento foram, igualmente, das mais endossadas pelos participantes ( $23.7 \%$ assinalou o item "Não saber se os meus problemas/necessidades/dificuldades são suficientemente graves para pedir ajuda"; $19.1 \%$ assinalou o item "Não saber qual o melhor tratamento para mim").

Tabela 4. Barreiras à Procura de Ajuda para a amostra total $(N=173)$ e respetivo endosso

\begin{tabular}{|c|c|c|}
\hline Tipo de Barreira & & $n(\%)$ \\
\hline & $\begin{array}{l}\text { Não me sentir confortável por frequentar consultas de psicologia e/ou } \\
\text { psiquiatria na minha zona de residência porque toda a gente se } \\
\text { conhece e eu não quero que descubram. }\end{array}$ & $12(6.9)$ \\
\hline & $\begin{array}{l}\text { Mesmo dirigindo-me a serviços de psicologia e/ou psiquiatria fora da } \\
\text { minha zona de residência, ter receio de encontrar pessoas conhecidas } \\
\text { que descubram que frequento consultas de psicologia e/ou } \\
\text { psiquiatria. }\end{array}$ & $7(4)$ \\
\hline & $\begin{array}{l}\text { Ter receio do que as outras pessoas ou conhecidos possam pensar } \\
\text { por frequentar consultas de psicologia e/ou psiquiatria. }\end{array}$ & $8(4.6)$ \\
\hline \multirow[t]{5}{*}{ Atitudinais } & $\begin{array}{l}\text { Por viver numa ilha, ter receio de o psicólogo e/ou psiquiatra poder } \\
\text { falar do meu caso com outros profissionais (p.e. com o meu médico } \\
\text { de família) e poder haver a possibilidade de me identificarem. }\end{array}$ & $9(5.2)$ \\
\hline & $\begin{array}{l}\text { Ter receio do que a minha família e/ou amigos possam pensar de mim } \\
\text { por frequentar consultas de psicologia e/ou de psiquiatria. }\end{array}$ & $5(2.9)$ \\
\hline & $\begin{array}{l}\text { Ter vergonha de falar com profissionais de saúde sobre os meus } \\
\text { problemas/necessidades/dificuldades. }\end{array}$ & $5(2.9)$ \\
\hline & $\begin{array}{l}\text { Achar que ninguém vai conseguir ajudar-me a lidar com os meus } \\
\text { problemas. }\end{array}$ & $3(1.7)$ \\
\hline & $\begin{array}{l}\text { Não ter referências de profissionais de psicologia e/ou psiquiatria na } \\
\text { minha ilha ou mesmo nos Açores que me possam ajudar nos meus } \\
\text { problemas/necessidades/dificuldades. }\end{array}$ & $15(8.7)$ \\
\hline \multirow[t]{6}{*}{ Conhecimento } & $\begin{array}{l}\text { Não saber se os meus problemas/necessidades/dificuldades são } \\
\text { suficientemente graves para pedir ajuda. }\end{array}$ & $37(21.4)$ \\
\hline & Não saber qual o melhor tratamento para mim. & $31(17.9)$ \\
\hline & Não saber onde procurar tratamento. & $4(2.3)$ \\
\hline & $\begin{array}{l}\text { Os serviços de psicologia e/ou psiquiatria ficarem muito distantes da } \\
\text { minha zona de residência. }\end{array}$ & $27(16.2)$ \\
\hline & $\begin{array}{l}\text { No dia das consultas eu ter que ficar longas horas fora de casa (sair de } \\
\text { casa muito cedo e regressar muito tarde). }\end{array}$ & $22(12.7)$ \\
\hline & $\begin{array}{l}\text { Não ter serviços de transportes disponíveis para ir e voltar das } \\
\text { consultas de psicologia e/ou psiquiatria. }\end{array}$ & $20(11.6)$ \\
\hline \multirow[t]{3}{*}{ Práticas/Estruturais } & $\begin{array}{l}\text { Mesmo colocando a possibilidade de ser acompanhado por um } \\
\text { psicólogo e/ou psiquiatra noutra ilha, as deslocações serem muito } \\
\text { caras e eu não as poder pagar. }\end{array}$ & $37(21.4)$ \\
\hline & $\begin{array}{l}\text { Mesmo tendo a possibilidade de ter consultas gratuitas no Hospital ou } \\
\text { nos Centros de Saúde, não ter acesso a estas consultas de forma } \\
\text { rápida. }\end{array}$ & $40(23.1)$ \\
\hline & Não ter tempo para ir às consultas de psicologia e/ou de psiquiatria. & $12(6.9)$ \\
\hline
\end{tabular}


Aceitabilidade do telefone ou telemóvel como meio para promover a adaptação psicológica dos sobreviventes de doença oncológica

\section{Posturas perante a Intervenção}

No geral, a maioria dos participantes concordou que, perante um problema psicológico ou necessidade psicossocial, uma intervenção via telefone seria útil (46.2\%) e eficaz (50.9\%) para Ihes fazer face, dadas as barreiras geográficas do local onde vivem. Cerca de $48.6 \%$ da amostra recorreria a uma intervenção desta natureza, sem dificuldade (35.8\%) e com o incentivo de amigos e/ou familiares (53.8\%). 48.6\% da amostra discorda que as pessoas importantes para si iriam considerar a participação na intervenção como prejudicial, sendo que a maioria dos participantes a recomendaria a outros (37.6\%). A maioria dos participantes concordou fortemente que a decisão de participar, ou não, na intervenção é sua (77.5\%).

\section{Eficácia e Utilidade Percebidas e Probabilidade de Participação na Intervenção}

No geral, a maioria da amostra considerou as intervenções via telefone eficazes (62.4\%) e úteis (59.5\%), sendo que $59.5 \%$ reportou ser provável participar. Como se pode verificar na Tabela 5, observou-se uma diferença estatisticamente significativa na utilidade percebida, com uma maior percentagem de sujeitos com idade superior a 65 anos a percecionar as intervenções via telefone úteis, comparativamente aos restantes grupos etários $(X 2(6)=15.45 ; p=0.02)$. No entanto, foi no grupo etário mais jovem (19 aos 50 anos) que se observou uma maior percentagem de indivíduos a reportar ser muito provável participar numa intervenção desta natureza $(X 2(6)=12.36$; $p=0.05)$. Em termos dos anos de sobrevivência não foram observadas diferenças estatisticamente significativas. 
Tabela 5. Eficácia percebida, Utilidade percebida, e Probabilidade de participar numa Intervenção por Telefone/Telemóvel e diferenças relativamente à idade, à ilha de residência e à escolaridade

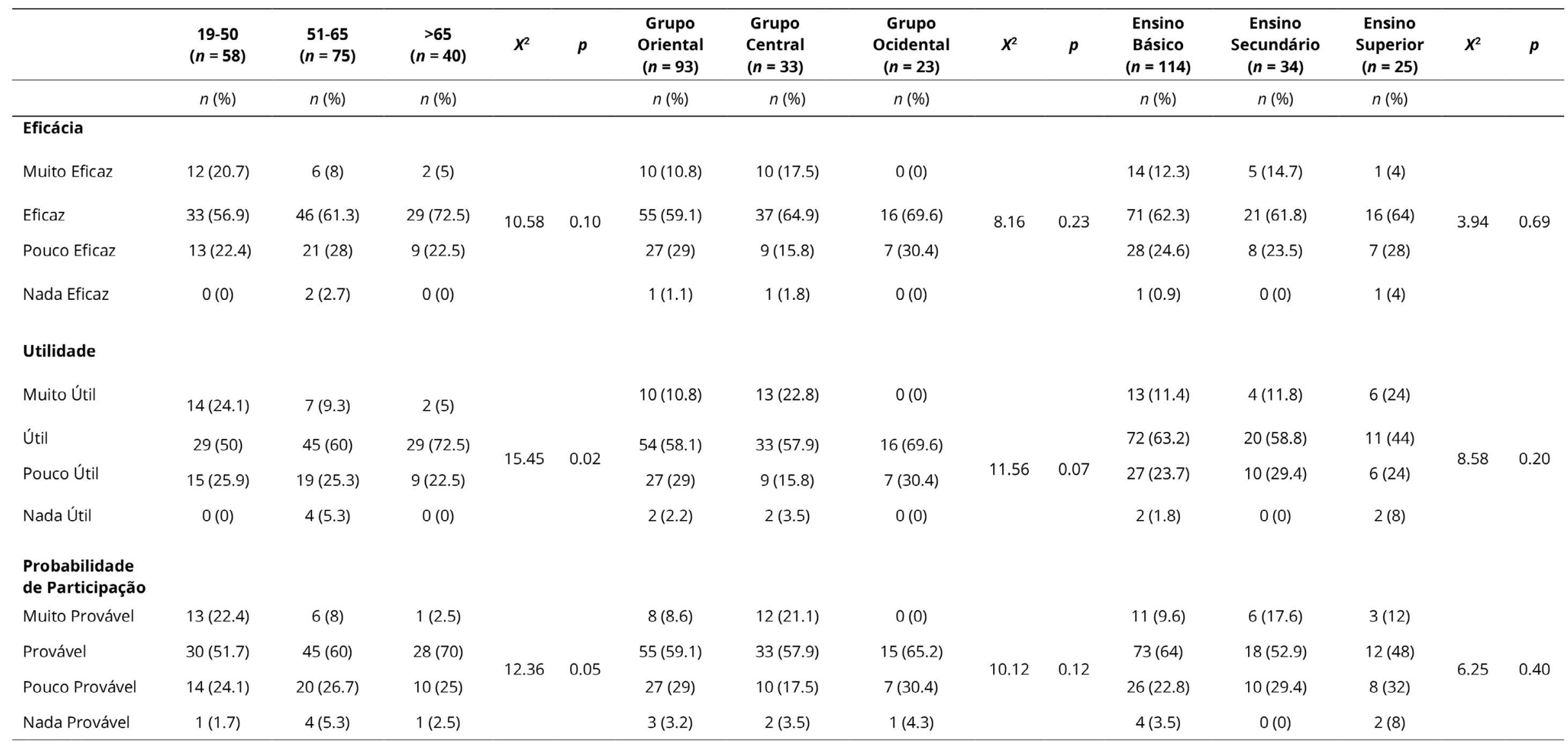




\section{Construção de uma intervenção via telefone ou telemóvel para promover a adaptação psicológica dos sobreviventes de doença oncológica: Preferências}

Em termos gerais, 39.3\% $(n=68)$ da amostra apontou a informação sobre quem construiu a intervenção, a organização, as instruções de funcionamento, a eficácia e os testemunhos como informação relevante a dar a conhecer a futuros participantes, sendo que $99.4 \%(n=172)$ considerou útil ser contactado pelo psicólogo, antes do início da intervenção, para receber uma explicação sobre a organização e o funcionamento da mesma.
Como se pode observar nas Tabelas 6 e 7, em todas as ilhas a duração preferida é de 30 a 45 minutos (X2 $(4)=9.97, p=0.04)$, com uma periodicidade quinzenal $(X 2(4)=13.85, p=0.00)$. Uma maior percentagem de sobreviventes com um tempo de sobrevida inferior a 5 anos reportou preferência por uma duração de cada sessão situada entre os 30 e os 45 minutos (X2 $(4)=11.59, p=0.02$ ) e com uma frequência quinzenal $(X 2(4)=9.85, p=0.04)$, comparativamente aos participantes com sobrevivência superior a 5 anos. 
Tabela 6. Preferências relativamente à Intervenção e diferenças relativamente à idade, à ilha de residência e à escolaridade

\begin{tabular}{|c|c|c|c|c|c|c|c|c|c|c|c|c|c|c|c|}
\hline & $\begin{array}{c}19-50 \\
(n=58)\end{array}$ & $\begin{array}{c}51-65 \\
(n=75)\end{array}$ & $\begin{array}{c}>65 \\
(n=40)\end{array}$ & $x^{2}$ & $p$ & $\begin{array}{c}\text { Grupo } \\
\text { Oriental } \\
(n=93)\end{array}$ & $\begin{array}{c}\text { Grupo } \\
\text { Central } \\
(n=33) \\
\end{array}$ & $\begin{array}{c}\text { Grupo } \\
\text { Ocidental } \\
(n=23)\end{array}$ & $x^{2}$ & $p$ & $\begin{array}{l}\text { Ensino Básico } \\
\quad(n=114)\end{array}$ & $\begin{array}{c}\text { Ensino } \\
\text { Secundário } \\
(n=34)\end{array}$ & $\begin{array}{c}\text { Ensino } \\
\text { Superior } \\
(n=25)\end{array}$ & $x^{2}$ & $p$ \\
\hline & $n(\%)$ & $n(\%)$ & $n(\%)$ & & & $n(\%)$ & $n(\%)$ & $n(\%)$ & & & $n(\%)$ & $n(\%)$ & $n(\%)$ & & \\
\hline \multicolumn{16}{|l|}{$\begin{array}{l}\text { Duração de } \\
\text { cada sessão }\end{array}$} \\
\hline $\begin{array}{l}\text { Menos de } 30 \\
\text { minutos }\end{array}$ & $10(17.2)$ & $18(24)$ & $4(10)$ & & & 25 (26.9) & $4(7)$ & $3(13)$ & & & $22(19.3)$ & $3(8.8)$ & $7(28)$ & & \\
\hline $\begin{array}{l}\text { Entre } 30 \text { a } 45 \\
\text { minutos }\end{array}$ & $34(58.6)$ & $44(58.7)$ & $32(80)$ & \multirow[t]{2}{*}{7.71} & \multirow[t]{2}{*}{0.10} & $54(58.1)$ & $41(71.9)$ & $15(65.2)$ & \multirow[t]{2}{*}{9.97} & \multirow[t]{2}{*}{0.04} & $71(62.3)$ & $27(79.4)$ & $12(48)$ & \multirow[t]{2}{*}{6.56} & \multirow[t]{2}{*}{0.16} \\
\hline $\begin{array}{l}\text { Entre } 45 \text { a } 60 \\
\text { minutos }\end{array}$ & $14(24.1)$ & $13(17.3)$ & $4(10)$ & & & $14(15.1)$ & $12(21.1)$ & $5(21.7)$ & & & $21(18.4)$ & $4(11.8)$ & $6(24)$ & & \\
\hline \multicolumn{16}{|l|}{ Periodicidade } \\
\hline Semanal & $13(22.4)$ & $7(9.3)$ & $3(7.5)$ & \multirow{3}{*}{8.60} & \multirow{3}{*}{0.07} & $14(15.1)$ & $9(15.8)$ & $0(0)$ & & & $12(10.5)$ & $7(20.6)$ & $4(16)$ & \multirow{3}{*}{4.09} & \multirow{3}{*}{0.39} \\
\hline Quinzenal & $29(50)$ & $36(48)$ & $18(45)$ & & & 39 (41.9) & $9(39.1)$ & 16 (69.6) & \multirow{2}{*}{$\begin{array}{c}13.8 \\
5\end{array}$} & \multirow{2}{*}{0.00} & $54(47.4)$ & $18(52.9)$ & $11(44)$ & & \\
\hline Mensal & $16(27.6)$ & $32(42.7)$ & 19 (47.5) & & & $40(43)$ & $13(22.8)$ & $14(60.9)$ & & & $48(42.1)$ & $19(26.5)$ & $10(40)$ & & \\
\hline
\end{tabular}

Tabela 7. Preferências relativamente à Intervenção e diferenças relativamente aos anos de sobrevivência

\begin{tabular}{|c|c|c|c|c|c|}
\hline & $\begin{array}{c}\text { Amostra Total } \\
(N=173)\end{array}$ & $\begin{array}{c}\text { Sobrevivente } \\
<5 \text { anos } \\
(n=83)\end{array}$ & $\begin{array}{c}\text { Sobrevivente } \\
>5 \text { anos } \\
(n=67)\end{array}$ & $x^{2}$ & $p$ \\
\hline & $n(\%)$ & $n(\%)$ & $n(\%)$ & & \\
\hline \multicolumn{6}{|c|}{ Duração de cada sessão } \\
\hline Menos de 30 minutos & $32(18.5)$ & $11(13.3)$ & $11(16.4)$ & \multirow{3}{*}{11.59} & \multirow{3}{*}{0.02} \\
\hline Entre 30 a 45 minutos & $110(63.6)$ & $55(66.3)$ & $44(65.7)$ & & \\
\hline Entre 45 e 60 minutos & $31(17.9)$ & $17(20.5)$ & $12(17.9)$ & & \\
\hline \multicolumn{6}{|l|}{ Periodicidade } \\
\hline Semanal & $23(13.3)$ & $9(10.8)$ & $9(13.4)$ & \multirow{3}{*}{9.85} & \multirow{3}{*}{0.04} \\
\hline Quinzenal & $83(48)$ & $49(59)$ & $28(33.7)$ & & \\
\hline Mensal & $67(38.7)$ & $25(30.1)$ & 30 (44.8) & & \\
\hline
\end{tabular}




\section{Discussão}

Ainda é escassa a investigação acerca da aceitabilidade e das preferências relativamente a intervenções com recurso à tecnologia destinadas a sobreviventes de cancro, especialmente a residir em regiões arquipelágicas. O presente estudo procurou explorar os padrões de utilização do telefone ou telemóvel dos sobreviventes de cancro dos Açores, os seus comportamentos de procura de ajuda, as barreiras percecionadas a esta procura, e a sua aceitabilidade e preferências relativamente a uma intervenção via telefone como forma de suporte psicológico.

Relativamente aos padrões de utilização do telefone ou telemóvel, uma maior proporção de sujeitos com idades compreendidas entre os 19 e os 50 anos, com ensino secundário ou superior, reportou utilizar mais este meio de comunicação, percecionando também serem os mais competentes na sua utilização, inclusivamente na leitura e escrita de mensagens de texto. Embora a investigação anterior evidencie que os padrões e a frequência de utilização do telefone ou telemóvel são bastante evidentes entre os vários grupos etários (Pew Research Center, 2018; Sillice et al., 2018), são os sobreviventes de cancro com idades mais jovens ( $<45$ anos) e com mais escolaridade que maior probabilidade apresentam de recorrer ao telemóvel numa base regular (Raghunathan et al., 2018), sendo também dele mais dependentes (Pew Research Center, 2017; Raghunathan et al., 2018). Foi no Grupo Central (ilhas Terceira e do Faial) que se observou uma maior percentagem de sobreviventes a reportar mais competência no manejo do telefone ou telemóvel e maior facilidade na escrita e leitura de mensagens escritas. Efetivamente, estas ilhas foram acompanhando o desenvolvimento tecnológico, nomeadamente ao nível das tecnologias da comunicação e difusão, com real impacto na economia local (e.g., aumento do poder de consumo), impacto esse que muito se deveu à influência americana da Base das Lajes (Sá, 2016). Esta realidade poder ter contribuído para a perceção dos residentes destas ilhas não só em termos da maior facilidade no acesso às tecnologias de comunicação, mas também de uma maior competência no seu manejo. Adicionalmente, foram os participantes com menos anos de sobrevida
( $<5$ anos) a reportar uma maior frequência no uso do telefone ou telemóvel. Após o final dos tratamentos os sobreviventes de cancro expressam necessidades de informação (e.g., manejo de sintomas, implicações da doença e dos tratamentos a curto e a longo prazo) e o recurso aos dispositivos móveis (e.g., telemóvel, smartphone) tem constituído uma forma rápida e frequentemente usada entre os sobreviventes para satisfazer tais necessidades (Richards et al., 2018).

Quanto aos comportamentos de procura de ajuda, a maioria da amostra considerou o recurso à medicação e ao apoio psicológico como recursos aceitáveis para fazer face a algum problema ou necessidade psicológica. Este dado encontra-se em consonância com os resultados de investigações anteriores que têm mostrado que um grande número de pessoas reconhece e recorre ao apoio psicológico em casos de morbilidade psicológica, sendo este tratamento o mais preferencial quando comparado com o recurso à medicação (McHugh et al., 2013). Para além disso, os estudos têm, também, sugerido que, perante dificuldades psicológicas, e comparativamente aos indivíduos dos meios urbanos, os de meios rurais preferem aceder à sua rede de cuidados informal (familiares, amigos), ao invés de procurar ajuda psicológica ou psiquiátrica especializada (e.g., Thorne \& Ebenar, 2020). Os nossos dados revelaram que uma maior percentagem de sobreviventes da ilha de São Miguel considerou aceitável o recurso à medicação psiquiátrica para fazer face a necessidades ou dificuldades de natureza mental ou emocional, comparativamente aos sobreviventes das restantes ilhas. Sendo a ilha de São Miguel a maior do arquipélago, e cujas áreas urbanizadas são, também, em maior número, os profissionais especializados em saúde mental (e.g., psiquiatras), aos quais as pessoas podem aceder quer no serviço regional de saúde, quer a nível privado, é maior em relação a outras ilhas mais pequenas ou isoladas (e.g., Flores). Isso pode contribuir para a maior literacia e aceitabilidade do suporte psiquiátrico nas ilhas maiores do arquipélago, o que se encontra em consonância com os dados de estudos anteriores (e.g., Gruebne et al., 2017). Este cenário empírico parece, igualmente, justificar a aceitabilidade do suporte psicológico verificada por uma maior percentagem de sobreviventes do Grupo Central e do Grupo Oriental, comparativamente aos do Grupo Ocidental, que inclui uma das ilhas mais distantes e rurais do arquipélago (Flores). 
Em termos gerais, e no que às barreiras à procura de ajuda diz respeito, os nossos resultados encontram-se em consonância com os já identificados em investigações anteriores conduzidas em regiões mais isoladas ou remotas, sendo as barreiras estruturais/ práticas e de conhecimento as mais endossadas pelos participantes (Lashbrook et al., 2018; You et al., 2016). Como forma de ultrapassar as barreiras estruturais/práticas, e à semelhança do já foi sugerido na investigação anterior, importa que o sistema e as políticas de saúde regionais possam estar sensíveis às barreiras identificadas no sentido de poderem definir medidas para aliviar os constrangimentos económicos e temporais associados à procura de ajuda especializada na Região (e.g., Cyr et al., 2019; Recklitis \& Syrjala, 2017). Ao nível das barreiras de conhecimento, os resultados mostraram que os sobreviventes dos Açores parecem, ainda, não possuir níveis satisfatórios de literacia em saúde mental, principalmente no que à gravidade dos sintomas e ao melhor tratamento para Ihes fazer face diz respeito. Assim, sensibilizar os sobreviventes dos Açores e fornecerIhes informação ou psicoeducação acerca dos problemas de saúde mental e das respostas existentes para com eles lidar, que também passe pelo estabelecimento de comunicação entre a equipa de cuidados de saúde e o sobrevivente, pode constituir uma via promissora de ultrapassar tais barreiras (e.g., Recklitis \& Syrjala, 2017; Xia et al., 2019).

No geral, os resultados do presente estudo sugerem que a maioria da amostra considerou que uma intervenção via telefone pode ser eficaz para fazer face a problemas der índole psicológica, sendo provável nela participar. De facto, a investigação já levada a cabo no âmbito das intervenções desta natureza tem evidenciado que as mesmas têm sido aceitáveis junto de sobreviventes de cancro (Crowder et al., 2019; Escriva et al., 2018; Forbes et al., 2019; Salsman et al., 2019; Seiler et al., 2017). Os nossos dados evidenciam que uma maior percentagem de sobreviventes com idade superior a 65 anos percecionou uma maior utilidade deste género de intervenção, comparativamente àqueles das restantes faixas etárias. Apesar de serem os sobreviventes mais velhos a reconhecer a utilidade de uma intervenção desta natureza, foi no grupo etário dos 19 aos 50 anos que se observou uma maior percentagem de sujeitos a expressar uma maior probabilidade em participar. A investigação anterior tem vindo a apontar que são os sobreviventes com idades mais jovens e com menos anos de sobrevida que apresentam uma maior probabilidade de recorrer e aceitar o recurso a aplicações e-health e m-health, no sentido de se manterem informados relativamente à doença e às suas implicações, sendo que aqueles que residem em áreas ruralizadas são também os que recorrem à tecnologia para a definição de objetivos e tomadas de decisão relativas à sua saúde, dadas as dificuldades sentidas no acesso aos cuidados de saúde (Jiang et al., 2017).

A presente investigação identificou algumas preferências dos sobreviventes açorianos relativamente a uma intervenção via telefone e que devem ser consideradas aquando do desenho e implementação de novas intervenções desta natureza durante a fase de sobrevivência. A informação acerca da intervenção (e.g., organização, instruções de funcionamento) deve ser fornecida aos sobreviventes. Os sobreviventes de todas as ilhas, principalmente aqueles com tempo de sobrevida inferior a 5 anos, preferiram uma duração de cada sessão situada entre os 30 e os 45 minutos e com uma periodicidade quinzenal. Estudos anteriores realizados no âmbito de intervenções mHealth com sobreviventes de cancro no âmbito da promoção da atividade física, têm mostrado que as preferências dos sobreviventes têm ido no sentido de sessões diárias e num registo semanal (e.g., Phillips et al., 2019). Contrariamente a estes dados empíricos, os resultados do presente estudo parecem sugerir que os sobreviventes do arquipélago com menos anos de sobrevivência preferem ter acesso a uma intervenção com sessões pontuais, com uma duração curta, e não tão extensas e rotineiras como acontece noutros estudos (e.g., Phillips et al., 2019), possivelmente no sentido de continuarem a manterse informados e a saber lidar com as consequências trazidas pelo diagnóstico e tratamentos e aos quais podem, ainda, não se ter adaptado (Jiang et al., 2017).

O presente estudo apresenta algumas limitações. A natureza transversal do estudo limita as inferências de causa efeito que possam dele derivar. Para além disso, a amostra do estudo não englobou todas as 9 ilhas do arquipélago, pelo que limita a generalização dos resultados a toda a região. Adicionalmente, estudos futuros devem avaliar o efeito de outras variáveis, não avaliadas na presente investigação (motivação, expectativas, personalidade), na aceitabilidade e nas preferências de uma intervenção desta natureza junto de sobreviventes de cancro. 
Apesar destas limitações, e do nosso conhecimento, este é o primeiro estudo a ser conduzido em Portugal e, especificamente, nos Açores. Este estudo constitui um contributo para a investigação em termos da aceitabilidade e das preferências relativamente a uma intervenção via telefone para sobreviventes num contexto insular, explorando os seus comportamentos de procura de ajuda e as barreiras à procura de suporte especializado na Região. O facto de os sobreviventes de cancro dos Açores, no geral, reportarem aceitabilidade por uma intervenção via telefone, os resultados do presente estudo têm implicações para a prática clínica, fornecendo algumas diretrizes para o desenho, o desenvolvimento e a implementação de um novo formato de intervenção, tendo em conta as suas preferências, e que permita ultrapassar as barreiras que previnem os sobreviventes de cancro do arquipélago de procurar ajuda especializada para as suas necessidades psicológicas. A presente investigação sublinha, portanto, a importância da avaliação de necessidades destes sobreviventes, no sentido de flexibilizar e atempar as respostas a prestar-Ihes e facilitar o suporte de que necessitam, sendo as intervenções via telefone uma via promissora a este nível. Uma intervenção desenhada especificamente para responder às necessidades dos sobreviventes de cancro e que consiga ultrapassar alguns constrangimentos no acesso aos cuidados de saúde mental é de grande importância quando, e do nosso conhecimento, uma intervenção com este objetivo é, ainda, inexistente na Região.

Em termos gerais, espera-se que os resultados resultantes do presente estudo possam orientar o desenvolvimento de uma intervenção via telefone que responda flexivelmente às necessidades que surgem e se vão modificando ao longo da trajetória da doença, identifique melhor os sobreviventes que podem requerer de ajuda especializada e facilite o suporte a prestar-Ihes, melhorando os seus indicadores de adaptação psicológica.

\section{Contribuições dos autores}

Sousa M participou na busca dos dados, concepção, delineamento e análise estatística dos dados de investigação, interpretação dos resultados e redação do artigo científico. Moreira $\mathrm{H}$ participou na conceção e delineamento, análise estatística, interpretação dos resultados e redação do artigo científico. Canavarro MC participou na concepção e delineamento do artigo científico. Barreto Carvalho C participou na concepção, delineamento e interpretação dos resultados.

\section{Conflitos de interesses}

Nenhum conflito financeiro, legal ou político envolvendo terceiros (governo, empresas e fundações privadas, etc.) foi declarado para nenhum aspecto do trabalho submetido (incluindo, mas não se limitando a subvenções e financiamentos, participação em conselho consultivo, desenho de estudo, preparação de manuscrito, análise estatística, etc.).

\section{Referências}

Allemani, C., Matsuda, T., Di Carlo, V., Harewood, R., Matz, M., Nikšić, M., Bonaventure, A., Valkov, M., Johnson, C. J., Estève, J., Ogunbiyi, O. J., Azevedo E Silva, G., Chen, W. Q., Eser, S., Engholm, G., Stiller, C. A., Monnereau, A., Woods, R. R., Visser, O.,...CONCORD Working Group. (2018). Global surveillance of trends in cancer survival 2000-14 (CONCORD-3): analysis of individual records for 37513025 patients diagnosed with one of 18 cancers from 322 population-based registries in 71 countries [Vigilância global das tendências na sobrevivência ao câncer 2000-14 (CONCORD-3): análise de registros individuais para 37.513.025 pacientes diagnosticados com um dos 18 cânceres de 322 registros de base populacional em 71 países]. Lancet, 391(10125), 1023-1075. https://doi. org/10.1016/S0140-6736(17)33326-3

Carolan, C. M., Smith, A., Davies, G. R., \& Forbat, L. (2018). Seeking, accepting and declining help for emotional distress in cancer: A systematic review and thematic synthesis of qualitative evidence [Buscar, aceitar e recusar ajuda para o sofrimento emocional no câncer: uma revisão sistemática e síntese temática de evidências qualitativas]. European journal of cancer care, 27(2), e12720. https://doi. org/10.1111/ecc.12720

Cavanagh, B. M., Wakefield, C. E., McLoone, J. K., Garvey, G., \& Cohn, R. J. (2016). Cancer survivorship services for indigenous peoples: where we stand, where to improve? A systematic review [Serviços de sobrevivência ao câncer para povos indígenas: onde nos encontramos, onde melhorar? Uma revisão sistemática]. Journal of cancer survivorship : research and practice, 10(2), 330-341. https:// doi.org/10.1007/s11764-015-0479-2

Coffey, L., Mooney, O., Dunne, S., Sharp, L., Timmons, A., Desmond, D., O'Sullivan, E., Timon, C., Gooberman-Hill, R., \& Gallagher, P. (2016). Cancer survivors' perspectives on adjustment-focused self-management interventions: a qualitative meta-synthesis [Perspectivas de sobreviventes de câncer sobre intervenções de autocuidado com foco no ajuste: uma metassíntese qualitative]. Journal of cancer survivorship: research and practice, 10(6), 1012-1034. https://doi.org/10.1007/s11764-016-0546-3 
Cornally, N., \& McCarthy, G. (2011). Help-seeking behaviour: a concept analysis [Comportamento de busca de ajuda: uma análise de conceito]. International journal of nursing practice, 17(3), 280-288. https://doi.org/10.1111/j.1440172X.2011.01936.X

Crowder, S. L., Douglas, K. G., Frugé, A. D., Carroll, W. R., Spencer, S. A., Locher, J. L., Demark-Wahnefried, W., Rogers, L. Q., \& Arthur, A. E. (2019). Head and neck cancer survivors' preferences for and evaluations of a post-treatment dietary intervention [Preferências de sobreviventes de câncer de cabeça e pescoço e avaliações de uma intervenção dietética pós-tratamento]. Nutrition Journal, 18(57), 1-8. https://doi.org/10.1186/s12937-019-0479-6

Cyr, M. E., Etchin, A. G., Guthrie, B. J., \& Benneyan, J. C. (2019). Access to specialty healthcare in urban versus rural US populations: a systematic literature review [Acesso a cuidados de saúde especializados em populações urbanas e rurais dos EUA: uma revisão sistemática da literatura]. BMC Health Services Research, 19(1), 1-17. https://doi. org/10.1186/s12913-019-4815-5

Escriva Boulley, G., Leroy, T., Bernetière, C., Paquienseguy, F., Desfriches-Doria, O., \& Préau, M. (2018). Digital health interventions to help living with cancer: A systematic review of participants' engagement and psychosocial effects [Intervenções de saúde digital para ajudar a viver com câncer: uma revisão sistemática do envolvimento dos participantes e efeitos psicossociais]. Psycho-oncology, 27(12), 2677-2686. https://doi.org/10.1002/pon.4867

Fonseca, A., Gorayeb, R., \& Canavarro, M. C. (2016). Women's use of online resources and acceptance of e-mental health tools during the perinatal period [Uso de recursos online pelas mulheres e aceitação de ferramentas de saúde mental eletrônica durante o período perinatal]. International journal of medical informatics, 94, 228-236. https://doi.org/10.1016/j.ijmedinf.2016.07.016

Forbes, C. C., Finlay, A., McIntosh, M., Siddiquee, S., \& Short, C. E. (2019). A systematic review of the feasibility, acceptability, and efficacy of online supportive care interventions targeting men with a history of prostate cancer [Uma revisão sistemática da viabilidade, aceitabilidade e eficácia das intervenções de cuidados de suporte online direcionadas a homens com histórico de câncer de próstata]. Journal of cancer survivorship : research and practice, 13(1), 75-96. https://doi.org/10.1007/s11764-0180729-1

Frensham, L. J., Parfitt, G., Stanley, R., \& Dollman, J. (2018). Perceived Facilitators and Barriers in Response to a Walking Intervention in Rural Cancer Survivors: A Qualitative Exploration [Facilitadores percebidos e barreiras em resposta a uma intervenção ambulante em sobreviventes de câncer rurais: uma exploração qualitative]. International journal of environmental research and public health, 15(12), 2824. https://doi.org/10.3390/ ijerph15122824
Gattiker, U. E. (1984). Managing computer-based office information technology: A process model for management [Gerenciando a tecnologia da informação de escritório baseada em computador: um modelo de processo para gerenciamento]. In H.W. Hendrick and O. Brown, Jr. (Eds.), Human factors in organizational design (pp.395- 403). Elsevier Science.

Gruebner, O., Rapp, M. A., Adli, M., Kluge, U., Galea, S., \& Heinz, A. (2017). Cities and mental health [Cidades e saúde mental]. Deutsches Ärzteblatt International, 114(8), 121-127. https:// doi.org/10.3238/arztebl.2017.0121

Inhestern, L., Beierlein, V., Bultmann, J. C., Möller, B., Romer, G., Koch, U., \& Bergelt, C. (2017). Anxiety and depression in working-age cancer survivors: a register-based study [Ansiedade e depressão em sobreviventes de câncer em idade produtiva: um estudo baseado em registro]. $B M C$ cancer, 17(1), 347. https://doi.org/10.1186/s12885-0173347-9

Jiang, Y., West, B. T., Barton, D. L., \& Harris, M. R. (2017). Acceptance and Use of eHealth/mHealth Applications for Self-Management Among Cancer Survivors [Aceitação e uso de aplicativos de eHealth / mHealth para autogestão entre sobreviventes de cancer]. Studies in health technology and informatics, 245, 131-135. https://pubmed.ncbi.nlm. nih.gov/29295067/

Lashbrook, M., Bernardes, C. M., Kirshbaum, M. N., \& Valery, P. C. (2018). Physical functioning and psychological morbidity among regional and rural cancer survivors: A report from a regional cancer centre [Funcionamento físico e morbidade psicológica entre sobreviventes de câncer regionais e rurais: um relatório de um centro regional de cancer]. The Australian journal of rural health, 26(3), 211-219. https://doi.org/10.1111/ajr.12419

Leppin, N., Nagelschmidt, K., Koch, M., Riera-Knorrenschild, J., Seifart, C., Rief, W., Barke, A., \& von Blanckenburg, P. (2019). Cancer patient utilisation of psychological care in Germany: The role of attitudes towards seeking help [Utilização de atendimento psicológico por pacientes com câncer na Alemanha: o papel das atitudes na busca de ajuda]. European Journal of Cancer Care, 28(6), e13165. https://doi.org/10.1111/ecc.13165

Loughery, J., \& Woodgate, R. L. (2015). Supportive care needs of rural individuals living with cancer: A literature review [Necessidades de cuidados de suporte de indivíduos rurais que vivem com câncer: uma revisão da literature]. Canadian oncology nursing journal/Revue canadienne de nursing oncologique, 25(2), 157-178. https://doi. org/10.5737/23688076252157166 
Matsui, T., \& Taku, K. (2016). A review of posttraumatic growth and help-seeking behavior in cancer survivors: effects of distal and proximate culture [Uma revisão do crescimento pós-traumático e comportamento de busca de ajuda em sobreviventes de câncer: efeitos da cultura distal e próxima]. Japanese Psychological Research, 58(1), 142-162. https://doi.org/10.1111/jpr.12105

Matsui, T., \& Tanimukai, H. (2017). The use of psychosocial support services among Japanese breast cancer survivors [O uso de serviços de apoio psicossocial entre sobreviventes de câncer de mama japonesas]. Japanese Journal of Clinical Oncology, 47(8), 743-748. https://doi. org/10.1093/jjco/hyx058

Mendes-Santos, C., Weiderpass, E., Santana, R., \& Andersson, G. (2019). A guided internet-delivered individually-tailored ACT-influenced cognitive behavioural intervention to improve psychosocial outcomes in breast cancer survivors (iNNOVBC): Study protocol [Uma intervenção cognitiva comportamental influenciada pelo ACT, orientada pela Internet, adaptada individualmente para melhorar os resultados psicossociais em sobreviventes do câncer de mama (iNNOVBC): protocolo de estudo]. Internet Interventions, 17, 100236. https://doi.org/10.1016/j. invent.2019.01.004

McHugh, R. K., Whitton, S. W., Peckham, A. D., Welge, J. A., \& Otto, M. W. (2013). Patient preference for psychological vs. pharmacological treatment of psychiatric disorders: a meta-analytic review [Preferência do paciente por tratamento psicológico versus tratamento farmacológico de transtornos psiquiátricos: uma revisão meta-analítica]. The Journal of Clinical Psychiatry, 74(6), 595-602. https://doi. org/10.4088/jcp.12r07757

Oberoi, D., White, V. M., Seymour, J. F., Miles Prince, H., Harrison, S., Jefford, M., Winship, I., Hill, D., Bolton, D., Kay, A., Millar, J., Doo, N. W., \& Giles, G. (2017). The influence of unmet supportive care needs on anxiety and depression during cancer treatment and beyond: a longitudinal study of survivors of haematological cancers [A influência das necessidades de cuidados de suporte não atendidas na ansiedade e depressão durante o tratamento do câncer e depois: um estudo longitudinal de sobreviventes de cânceres hematológicos]. Supportive care in cancer: official journal of the Multinational Association of Supportive Care in Cancer, 25(11), 3447-3456. https://doi.org/10.1007/ s00520-017-3766-9

Ojewole, F. O., Madu, A. M., \& Nwozichi, C. U. (2018). Association between psychological distress and unmet information needs among female cancer patients in two selected teaching hospitals in South-West Nigeria [Associação entre sofrimento psicológico e necessidades de informação não atendidas entre pacientes com câncer em dois hospitais universitários selecionados no sudoeste da Nigéria]. CHRISMED Journal of Health and Research, 5(1), 11-17. https://doi.org/10.4103/cjhr.cjhr_62_17
Okuyama, S., Jones, W., Ricklefs, C., \& Tran, Z. V. (2015). Psychosocial telephone interventions for patients with cancer and survivors: a systematic review [Intervenções psicossociais telefônicas para pacientes com câncer e sobreviventes: uma revisão sistemática]. Psycho-Oncology, 24(8), 857-870. https://doi.org/10.1002/pon.3704

Pew Research Center (2017). Mobile Fact Sheet. http://www. pewinternet.org/fact-sheet/mobile/

Pew Research Center (2018). Mobile Fact Sheet. http://www. pewinternet.org/fact-sheet/mobile/

Phillips, S. M., Courneya, K. S., Welch, W. A., Gavin, K. L., Cottrell, A., Nielsen, A., Solk, P., Blanch-Hartigan, D., Cella, D., Ackermann, R. T., Spring, B., \& Penedo, F. (2019). Breast cancer survivors' preferences for mHealth physical activity interventions: findings from a mixed methods study [Preferências de sobreviventes de câncer de mama para intervenções de atividade física mHealth: resultados de um estudo de métodos mistos]. Journal of cancer survivorship : research and practice, 13(2), 292-305. https:// doi.org/10.1007/s11764-019-00751-3

Price, J., \& Brunet, J. (2020). Telehealth coaching for rural-living young adult cancer survivors: A protocol [Telehealth coaching para sobreviventes de câncer jovens adultos que vivem em áreas rurais: um protocolo]. Health Education Journal, 79(2), 212-224. https://doi. org/10.1177/0017896919871328

Raghunathan, N. J., Korenstein, D., Li, Q. S., Tonorezos, E. S., \& Mao, J. J. (2018). Determinants of mobile technology use and smartphone application interest in cancer patients [Determinantes do uso de tecnologia móvel e interesse em aplicativos de smartphones em pacientes com câncer]. Cancer Medicine, 7(11), 5812-5819. https://doi.org/10.1002/ cam4.1660

Recklitis, C. J., \& Syrjala, K. L. (2017). Provision of integrated psychosocial services for cancer survivors post-treatment [Prestação de serviços psicossociais integrados para sobreviventes de câncer pós-tratamento]. The Lancet Oncology, 18(1), e39-e50. https://doi.org/10.1016/s14702045(16)30659-3

Richards, R., Kinnersley, P., Brain, K., McCutchan, G., Staffurth, J., \& Wood, F. (2018). Use of mobile devices to help cancer patients meet their information needs in non-inpatient settings: systematic review [Uso de dispositivos móveis para ajudar pacientes com câncer a atender às suas necessidades de informação em ambientes externos: revisão sistemática]. JMIR mHealth and uHealth, 6(12), e10026. https://doi.org/10.2196/10026

Sá, T. M. D. (2016). Os Estados Unidos e os Açores: A Base das Lajes e o retraimento americano. Relações Internacionais, 51, 57-74. http://www.scielo.mec.pt/scielo.php?script=sci arttext\&pid=S1645-91992016000300005\&lng=pt\&t|ng=pt 
Salsman, J. M., Pustejovsky, J. E., Schueller, S. M., Hernandez, R., Berendsen, M., McLouth, L., \& Moskowitz, J. T. (2019). Psychosocial interventions for cancer survivors: A meta-analysis of effects on positive affect [Intervenções psicossociais para sobreviventes de câncer: uma metaanálise dos efeitos sobre o afeto positive]. Journal of cancer survivorship : research and practice, 13(6), 943-955. https://doi.org/10.1007/s11764-019-00811-8

Seiler, A., Klaas, V., Tröster, G., \& Fagundes, C. P. (2017). eHealth and $\mathrm{mHealth}$ interventions in the treatment of fatigued cancer survivors: A systematic review and meta-analysis [Intervenções de eHealth e mHealth no tratamento de sobreviventes de câncer fatigados: uma revisão sistemática e meta-análise]. Psycho-Oncology, 26(9), 12391253. https://doi.org/10.1002/pon.4489

Sillice, M. A., Dunsiger, S., Jennings, E., Lantini, R., \& Bock, B. C. (2018). Differences in mobile phone affinity between demographic groups: implications for mobile phone delivered interventions and programs [Diferenças na afinidade de telefone celular entre grupos demográficos: implicações para intervenções e programas fornecidos por telefone cellular]. Mhealth, 4, 1-11. https://dx.doi. org/10.21037\%2Fmhealth.2018.09.06

Stanton, A. L., Rowland, J. H., \& Ganz, P. A. (2015). Life after diagnosis and treatment of cancer in adulthood: Contributions from psychosocial oncology research [Vida após o diagnóstico e tratamento do câncer na idade adulta: contribuições da pesquisa em oncologia psicossocial]. American Psychologist, 70(2), 159-174. https:// doi.org/10.1037/a0037875
Thorne, K. L., \& Ebener, D. (2020). Psychosocial predictors of rural psychological help seeking [Preditores psicossociais da procura de ajuda psicológica rural]. Journal of Rural Mental Health, 44(4), 232-242. https://doi.org/10.1037/ rmh0000159

World Health Organization. (2008). Cancer control: knowledge into action - diagnosis and treatment WHO guide for effective programmes [Controle do câncer: conhecimento em ação - diagnóstico e tratamento Guia da OMS para programas eficazes]. World Health Organization. https://www.who. int/cancer/modules/en/

Xia, J., Wu, P., Deng, Q., Yan, R., Yang, R., Lv, B., Wang, J., \& Yu, J. (2019). Relationship between health literacy and quality of life among cancer survivors in China: a cross-sectional study [Relação entre alfabetização em saúde e qualidade de vida entre sobreviventes de câncer na China: um estudo transversal]. BMJ open, 9(12), e028458. https://doi. org/10.1136/bmjopen-2018-028458

Yi, J. \& Syrjala, K. L. (2017). Anxiety and Depression in Cancer Survivors [Ansiedade e depressão em sobreviventes ao câncer]. Medical Clinics, 101(6), 1099-1113. https://dx.doi. org/10.1016\%2Fj.mcna.2017.06.005

Youl, P. H., Dasgupta, P., Youlden, D., Aitken, J. F., Garvey, G., Zorbas, H., Wallington, I., \& Baade, P. D. (2016). A systematic review of inequalities in psychosocial outcomes for women with breast cancer according to residential location and Indigenous status in Australia [Uma revisão sistemática das desigualdades nos resultados psicossociais para mulheres com câncer de mama de acordo com a localização residencial e status indígena na Austrália]. Psycho-Oncology, 25(10), 1157-1167. https://doi. org/10.1002/pon.4124 